\title{
KAJIAN LAJU EKSPLOITASI HASIL TANGKAPAN DI SEKITAR KAWASAN TAMAN WISATA PERAIRAN (TWP) PULAU PIEH
}

\author{
Defra Monika $^{1)}$, Arlius $^{2)}$, Masrizal ${ }^{3)}$ \\ 1) Staf Pengajar Progran Studi Perikanan Tangkap Politeknik Kelautan dan Perikanan Pariaman \\ ${ }^{2}$ Staf Pengajar Program Studi Pengelolaan Sumberdaya Perairan, Pesisir dan Kelautan Universitas Bung Hatta \\ ${ }^{3)}$ Staf Pengajar Program Studi Peternakan Fakultas Peternakan Universitas Andalas \\ Email :defra_monika@yahoo.com
}

\begin{abstract}
The study is done at October to December 2018 in Tourist Waters Park Area Pieh Island.Choice of location for the Marine Park Area Pieh Island and the sea all around, located in two cities is Padang City and Pariaman city and one district Padang Pariaman doing by deliberately (purposive sampling). Research aims to known the exploitation of fish and aimed to know the state of resources fish in Marine Park Area Pieh Island.

The research results show that the rate of the exploits of fish in Marine Park Area Pieh Island the longest wait with an average value of the the exploits of 0,75731 , the rate of the exploits of has the highest poverty rate is found in species of Stolephorus sp , Euthynnus sp, Rastrelliger spp, Sardinella spp, Selaroides sp, Leiognathus spp, Scomberoides sp, Caranx sp, Alectis sp, Sphyraena sp, Acanthocybium sp, Lutjanus sp, Trihiurusavala sp, Katsuwonus sp, Epinephelus spp, Arius spp, Lolligo spp with the size of the taxes exploits of $>0,5$. The lowest exploitation is found in species of fish, Decapterus sp, Therapon spp, Thunnus sp still under the $<0,5$, still can be used optimally. Instrument get used to have a low selektifitas where all of the size of fish arrested so that reduces the chance to the fish grow can indeed be resulted in excess catch (overfishing).
\end{abstract}

\section{Keyword : exploitation, Utilization, Marine Park Area Pieh Island}

\begin{abstract}
ABSTRAK
Kajian eksploitasi hasil tangkapan di sekitar Kawasan Taman Wisata Perairan Pulau Pieh berperan untuk mengetahui tingkatan eksploitasi. Tujuan penelitian ini adalahUntuk mengetahui Hasil Tangkapan ikan dan mengetahui hasil eksploitasi ikan. Penentuan lokasi penelitian dilakukan dengan sengaja (purposive sampling) yakni pada TPI Pasie Nan Tigo Kota Padang, TPI Karan Aur Kota Pariaman, TPI Pasar Ulakan Kabupaten Padang Pariaman dan PPI Pasir Baru Kabupaten Padang Pariaman.Hasil penelitian menunjukkan Tingkat eksploitasi ikan di TWP Pulau Pieh dengan rata - rata nilai eksploitasi 0,75731, laju eksploitasi tertinggi terdapat pada jenis ikan Teri, Tongkol Kembung, Sarden, Selar, Peperek, Talang - Talang, Kuwe, Barakuda, Tenggiri, Kakap, Layur, Cakalang, Kerapu, Gole - Gole, Manyung dan Cumi - Cumi dengan besaran eksploitasi > 0,5. Laju Eksploitasi Terendah terdapat pada jenis ikan Layang, Tuna dan Kerong - kerong yang masih dibawah angka ketetapan $<0,5$, sehingga masih dapat dimanfaatkan secara optimal. Kondisi sumberdaya ikan di TWP Pulau Pieh sudah mengalami overfishing atau kelebihan tangkap dikarenakan tingginya laju eksploitasi penangkapan. Alat
\end{abstract}


tangkap yang digunakan memiliki tingkat selektifitas yang rendah sehingga dapat mengakibatkan kelebihan tangkap.

Kata Kunci: Eksploitasi, Pemanfaatan, TWP Pulau Pieh

\section{PENDAHULUAN}

\section{Latar Belakang}

Kawasan Taman Wisata Perairan (TWP) Pulau Pieh merupakan salah satu kawasan konservasi perairan nasional yang terletak di Provinsi Sumatera Barat tepatnya di sebelah barat wilayah administratif Kota Padang, Kabupaten Padang Pariaman dan Pariaman. Sebelum diserahkan ke Kementerian Kelautan dan Perikanan, kawasan ini merupakan Kawasan Pelestarian Alam (KPA) dengan fungsi sebagai Taman Wisata Alam Laut (TWAL) Pulau Pieh yang pengelolaannya berada di bawah Balai Konservasi Sumber daya Alam (BKSDA) Sumatera Barat Kementerian Kehutanan, melalui SK Menteri Kehutanan dan Perkebunan No: 070/Kpts-II/2000 pada tanggal 28 Maret 2000.Kawasan ini diserah terimakan dari Kementerian Kehutanan ke Kementerian Kelautan dan Perikanan melalui berita acara serah terima Nomor BA.01/Menhut-IV/2009 dan Nomor BA.108/MEN.KP/III/2009 pada tanggal 4 Maret 2009. Kemudian kawasan ini ditetapkan sebagai Kawasan Konservasi Perairan Nasional (KKPN) dengan fungsi sebagai Taman Wisata Perairan (TWP) Pulau Pieh dan Laut di Sekitarnya di Provinsi Sumatera Barat melalui Keputusan Menteri Kelautan dan Perikanan Nomor : KEP. 70/MEN/2009 tanggal 3 September 2009.

\footnotetext{
Zonasi dalam kawasan konservasi adalah pembagian kawasan menjadi beberapa zona melalui penetapan batas-batas fungsional sesuai dengan potensi sumber daya dan daya dukung, serta proses-proses ekologis yang berlangsung di dalamnya
}

sebagai satu kesatuan ekosistem. Berdasarkan pada Peraturan Menteri Kelautan dan Perikanan Nomor PER.30/ MEN/2010 tentang Rencana Pengelolaan dan Zonasi Kawasan Konservasi Perairan, disebutkan bahwa zonasi di dalam kawasan konservasi perairan terdiri dari zona inti, zona perikanan berkelanjutan, zona pemanfaatan, dan zona lainnya.Zona inti di dalam kawasan TWP Pulau Pieh tersebar dalam 5 wilayah, masing-masing di perairan sekitar pulau-pulau yang terdapat di dalam kawasan dengan luas zona inti dalam kawasan TWP Pulau Pieh total mencapai $801,59 \mathrm{Ha}$, atau 2,01 \% dari luas total kawasan. Di dalam 5 zona inti ini terdapat habitat terumbu karang seluas 209,079 Ha. Zona perikanan berkelanjutan dalam kawasan konservasi perairan diatur untuk mengakomodir kegiatan-kegiatan perikanan dengan catatan bahwa kegiatan tersebut dilakukan dengan cara-cara yang ramah lingkungan. Zona pemanfaatan dalam KKP diatur untuk mengakomodir kegiatan kegiatan pemanfaatan kawasan dengan catatan tidak ada aktivitas pengambilan (no take) sumber daya yang ada di dalam kawasan. Zona lainnya merupakan zona di luar Zona Inti, Zona Perikanan Berkelanjutan, dan Zona Pemanfaatan yang karena fungsi dan kondisinya ditetapkan sebagai zona tertentu. Zona tertentu dapat berupa antara lain zona perlindungan dan zona rehabilitasi (KKP - RI 2014).

Hal utama penyebab krisis sumberdaya ikan adalah intervensi manusia yang tidak terkendali terhadap sumberdaya perikanan yang ada sehingga ekploitasi sumberdaya tersebut dapat menyebabkan ketidakseimbangan antara input 
penangkapan dan potensi sumberdaya ikan maka dapat mengarah pada kondisi tangkapan lebih (overfishing), kelebihan kapasitas, penurunan produksi, inefisiensi penangkapan, penurunan rente sumberdaya, serta terjadinya degradasi dan depresiasi sumberdaya (Sangaji et al., 2014). Dengan demikian pembangunan perikanan dapat direncanakan sedemikian rupa sehingga potensi sumberdaya perikanan laut tetap berkelanjutan (sustainable) untuk mendukung kebijakan pengelolaan wilayah pesisir dan lautan (Tangke, 2010). Data yang dihimpun pada tahun 2017 produksi ikan yang sering tertangkap oleh nelayan dimana jumlahnya 52.411,3 ton (Data Olahan Bappeda dan BPS Kota Padang, Kota Pariaman dan Kabupaten Padang Pariaman, 2018).

Laju eksploitasi berguna untuk menganalisis keberlanjutan pengelolaan perikanan. Salah satu aspek berkelanjutan perikanan adalah memelihara keberlanjutan stok atau biomassa agar tidak melewati daya dukungnya (Charles, 2001). Penelitian tentang laju eksploitasi ikan-ikan hasil tangkapan di Karimunjawa pernah dilakukan sebelumnya oleh (Yuliana et al., 2016) yang memfokuskan pada laju eksploitasi empat jenis ikan karang. Hasil penelitian tersebut adalah ikan ekor kuning (Caesio cuning) memiliki laju eksploitasi 0,41 ; pisang-pisang (Caesio caerulaurea) 0,57; sunu macan (Plectropomus oligocanthus) 0,77; dan jenggot (Parupeneus barberinus) 0,26.

Berdasarkan uraian diatas untuk mencegah menurunnya populasi dan potensi ikan yang ada, maka perlu pengembangan kearah yang lebih baik lagi untuk mendapatkan hasil yang maksimal. Eksploitasi merupakan tindakan untuk memanfaatkan ikan yang ada agar mendapatkan keuntungan. Bagaimana kondisi lestari (Maximum Sustainable Yieald) dan upaya pemanfaatan ikan di Taman Wisata Perairan (TWP) Pulau Pieh supaya tetap bertanggung jawab dan berkelanjutan. Untuk menjawab pertanyaan itu, maka dilakukan kajian potensi dan eksploitasi ikan di kawasan Taman Wisata Perairan (TWP) Pulau Pieh meliputi Kabupaten/Kota : Padang, Padang Pariaman dan Kota Pariaman Provinsi Sumatera Barat.

\section{Tujuan Penelitian}

Penelitian ini bertujuan untuk mengkaji seberapa besar eksploitasi ikan di kawasan Taman Wisata Perairan (TWP) Pulau Pieh yang terdiri dari :

1. Untuk mengetahui hasil tangkap ikan di sekitar kawasan Taman Wisata Perairan (TWP) Pulau Pieh

2. Untuk mengetahui laju eksploitasi hasil tangkapan ikan di sekitar kawasan Taman Wisata Perairan (TWP) Pulau Pieh

\section{MATERI DAN METODE PENELITIAN}

\section{Waktu dan Tempat Penelitian}

Penelitian ini dilaksanakan pada bulan Oktober - Desember 2018 di kawasan Taman Wisata Perairan (TWP) Pulau Pieh.

\section{Bahan dan Alat Penelitian}

Alat dan bahan yang digunakan dalam kegiatan monitoring pendaratan hasil tangkapan ikan adalah: kamera, lembar data, mistar/roll meter, timbangan, label jenis alat tangkap, dan alat tulis (pensil). Sedangkan bahan yakni sampel ikan yang tertangkap oleh nelayan sekitar TWP Pulau Pieh.

\section{Metode Penelitian}

\section{Data Sekunder}

Data sekunder dikumpulkan bersumber dari instansi terkait, yaitu sebagai berikut :
a. Informasi umum kegiatan perikanan yang ada di kawasan.
b. Jumlah nelayan.
c. Jenis dan jumlah kapal dari unit penangkapan yang beroperasi. 
d. Jenis dan jumlah alat tangkap yang dioperasikan.

\section{Data Primer}

Pengumpulan data dilakukan secara purposive sampling, yaitu nelayan yang melakukan aktivitas penangkapan di kawasan Taman Wisata Perairan Pulau Pieh. Adapun jenis data yang dikumpulkan adalah sebagai berikut:

\section{Jenis data yang dikumpulkan}

Jenis data hasil tangkapan yang dikumpulkan adalahJenis data yang dikumpulkan adalah :

- Tanggal waktu pengumpulan data

- Nama nelayan penangkap

- Jenis alat tangkap

- Jumlah trip penangkapan

- Daerah penangkapan

- Hasil tangkapan $(\mathrm{kg}) /$ jenis ikan

- Panjang per ikan $(\mathrm{cm}) /$ jenis ikan

- Berat per ikan (gr) / jenis ikan

\section{ANALISIS DATA}

\section{Laju Mortalitas Alami}

Mortalitas total stok ikan di alam didefenisikan sebagai laju penurunanpelimpahan individualikan berdasarkan waktu eksponensial.Laju mortalitas alami (M) diduga dengan menggunakan rumus empiris Pauly 1984 dalam (Sparre \& Venema, 1999), yaitu :

$$
\begin{aligned}
& \ln M=-0,0152-0,2790 \\
& * \ln L_{\infty}+0,6543 \\
& * \ln K+0,4630 * \ln T
\end{aligned}
$$

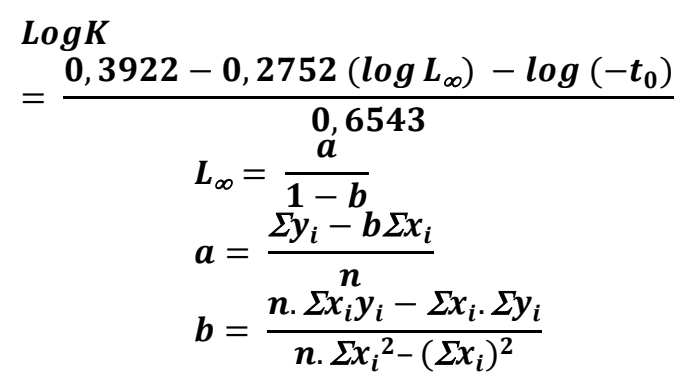

dimana :
$M=$ laju mortalitas alami

$L \infty=$ panjang asimtotik

$K=$ koefisien laju pertumbuhan

$T=$ rata-rata suhu permukaan laut ( $\mathrm{spl}$ ) dalam setahun

$t_{0}=$ umur teoritis pada saat ikan panjang nol

$a=$ intersep

$b=$ koefisien regresi

$x_{i}=$ panjang ikan umur $n$

$y_{i}=$ panjang ikan umur $n+1$

\section{Laju Mortalitas Total}

Mortalitas total akan diduga dengan persamaan yang dikemukakan oleh (Beverton \& Holt, 2012) dalam (Sparre \& Venema, 1999) yaitu :

$$
\begin{aligned}
& Z=K\left[\frac{L_{\infty}-\bar{L}}{\bar{L}-L^{\prime}}\right] \\
& \log K \\
& =\frac{0,3922-0,2752\left(\log L_{\infty}\right)-\log \left(-t_{0}\right)}{0,6543} \\
& L_{\infty}=\frac{\stackrel{a}{ }^{-b}}{1-b} \\
& a=\frac{\Sigma y_{i}-b \Sigma x_{i}}{n} \\
& b=\frac{n \cdot \Sigma x_{i} y_{i}-\Sigma x_{i} \cdot \Sigma y_{i}}{n \cdot \Sigma x_{i}^{2}-\left(\Sigma x_{i}\right)^{2}} \\
& \ln M=-0,0152-0,2790 \\
& * \ln L_{\infty}+0,6543 \\
& * \ln K+0,4630 * \ln T
\end{aligned}
$$

Dimana :

$Z=$ laju mortalitas total

$M=$ laju mortalitas alami

$L \infty=$ panjang asimtotik

$K=$ koefisien laju pertumbuhan

$\bar{L}=$ panjang rata-rata ikan tertangkap

$L^{\prime}=$ batas panjang ikan terkecil tertangkap

$t_{0}=$ umur teoritis pada saat ikan panjang nol

$a=$ intersept

$b=$ koefisien regresi

$x_{i}=$ panjang ikan umur $n$

$y_{i}=$ panjang ikan umur $n+1$

\section{Laju Mortalitas Penangkapan}

Mortalitas penangkapan disebabkan oleh kecepatan eksploitasi suatu stok karena kegiatan manusia (penangkapan) selama periode waktu tertentu, dimana semua faktor penyebab kematian berpengaruh terhadap 
populasi ikan. Laju mortalitas penangkapan dihitung dengan menggunakan rumus (Beverton dan Holt, (1957); (Sparre dan Venema, (1999), sebagai berikut Mortalitas penangkapan $(\mathrm{F})$ diduga dengan persamaan $\mathrm{Z}=\mathrm{F}+\mathrm{M}$ sehingga laju mortalitas penangkapan dihitung dengan menggunakan rumus sebagai berikut:

$\boldsymbol{F}=\boldsymbol{Z}-\boldsymbol{M}$

Dimana :

$F=$ laju mortalitas penangkapan

$Z=$ laju mortalitas total

$M=$ laju mortalitas alami

\section{Laju Eksploitasi}

Dari hasil yang didapat pada mortalitas maka untuk menduga tingkat eksploitasinya (E) dapat diperoleh dengan menggunakan rumus (Beverton dan Holt, 1957 dalam (Sparre \& Venema, 1999), yaitu:

$$
\mathbf{E}=\mathbf{F} / \mathbf{Z}
$$

Dimana :

$\mathrm{F}=$ Nilai mortalitas penangkapan

$\mathrm{Z}=$ Mortalitas total

\section{HASIL DAN PEMBAHASAN}

\section{a. Mortalitas Alami}

Dapat dilihat pada Tabel1. mortalitas alami dimana kematian ikan disebabkan oleh proses alamiah selama periode waktu mempunyai nilai tertinggi pada ikan kerong - kerong dengan nilai 0,22585. Sedangkan nilai mortalitas alami terendah didapatkan pada ikan kembung dengan nilai 0,00385.

Nilai mortalitas alami tidak selalu sejalan atau berlawanan dengan nilai mortalitas total (Z), hal ini disebabkan pengaruh yang kuat dari temperatur bulanan perairan.

Menurut (King, 1995), bahwa mortalitas alami disebabkan oleh berbagai faktor diantaranya pemangsaan, penyakit, stress, pemijahan, umur, dan ketersediaan makanan. Menurut (Pauly, 1984), terdapat hubungan yang erat antara mortalitas alami ikan dengan suhu perairan, yaitu semakin hangat suhu lingkungan perairan, maka semakin tinggi mortalitas alami(Sparre \& Venema, 1999), menyatakan bahwa kematian alami disebabkan oleh berbagai faktor antara lain karena predasi, penyakit, stres pada waktu pemijahan, kelaparan dan usia tua. Oleh karena itu dapat diduga pula bahwa penurunan laju mortalitas alami disebabkan oleh menurunnya jumlah ikan yang tumbuh hingga berusia tua dan mengalami kematian secara alami akibat telah tertangkap lebih dulu karena aktifitas penangkapan. Tingginya laju mortalitas penangkapan dan menurunnya laju mortalitas alami juga dapat menunjukkan dugaan terjadinya kondisi growth overfishing yaitu sedikitnya jumlah ikan tua (Sparre \& Venema, 1999)karena ikan muda tidak sempat tumbuh akibat tertangkap sehingga tekanan penangkapan terhadap stok tersebut seharusnya dikurangi hingga mencapai kondisi optimum yaitu laju mortalitas penangkapan sama dengan laju mortalitas alami.

\section{b. Mortalitas Penangkapan}

(Effendie, 1997), mendefinisikan bahwa mortalitas penangkapan disebabkan kecepatan eksploitasi suatu stok karena kegiatan manusia (penangkapan) selama periode waktu tertentu, dimana semua faktor penyebab kematian berpengaruh terhadap populasi. Sedangkan pengharapan kematian tahunan penyebab alamiah adalah peluang dimana seekor ikan mati oleh proses alamiah selama periode waktu yang diamati (Aziz, 1989)

Mortalitas penangkapan merupakan fungsi dari upaya penangkapan (fishing effort) yang mencakup jumlah dan jenis ikan, efektivitas dari alat tangkap dan waktu yang digunakan untuk melakukan 
penangkapan (King, 1995). Mortalitas karena penangkapan $(\mathrm{F})$ cenderung bervariasi dari tahun ke tahun bergantung kepada upaya penangkapan (effort). Mortalitas tertinggi akibat penangkapan yang diperoleh selama penelitian adalah 0,53291 pada jenis ikan Kuwe, sedangkan mortalitas terendah akbibat penangkapan adalah ikan layang dengan nilai 0,03531.

Hal ini menunjukkan bahwa ikan jenis kuwe lebih banyak mengalami kematian akibat adanya aktivitas penangkapan. Akibat dari tingginya laju mortalitas penangkapan terhadap ikan kuwe akan menurunkan mortalitas alaminya. Sedangkan pada ikan layang mortalitas penagkapan rendah diduga tidak banyaknya potensi ikan tersebut dan juga aktifitas penangkapan ikan layang tidak terlalu intensif dan tidak merupakan komoditas utama yang ditangkap oleh nelayan sekitar TWP Pulau Pieh.

Menurut (King, 1995)semakin besar upaya penangkapan dan jumlah alat tangkap yang beroperasi, maka semakin besar pula mortalitas ikan karena penangkapan. Tingginya laju mortalitas penangkapan dan menurunnya laju mortalitas alami jugadapat menunjukkan dugaan terjadinya kondisi growth overfishing yaitu sedikitnya jumlah ikan tua (Sparre \& Venema, 1999) karena ikan muda tidak sempat tumbuh akibat tertangkap sehingga tekanan penangkapan terhadap stok ikan tersebut seharusnya dikurangi hingga mencapai kondisi optimum yaitu laju mortalitas penangkapan sama dengan laju mortalitas alami.

Tabel 1. Laju Mortalitas Alami, Mortalitas Penangkapan, Mortalitas dan Laju Eksploitasi Menurut Jenis Ikan.

\begin{tabular}{|c|c|c|c|c|c|}
\hline \multirow{2}{*}{ No. } & \multirow{2}{*}{ Jenis Ikan } & \multicolumn{3}{|c|}{ Laju Mortalitas } & \multirow{2}{*}{$\begin{array}{l}\text { Laju } \\
\text { Ekploitasi }\end{array}$} \\
\hline & & Alami & Penangkapan & Total & \\
\hline 1 & Teri, Stolephorus sp & 0,01754 & 0,20897 & 0,22651 & 0,92258 \\
\hline 2 & Tongkol, Euthynnus sp & 0,01214 & 0,19536 & 0,20750 & 0,94148 \\
\hline 3 & Kembung, Rastrelliger spp & 0,00385 & 0,14539 & 0,14924 & 0,97421 \\
\hline 4 & Sarden, Sardinella spp & 0,03744 & 0,14473 & 0,18217 & 0,79448 \\
\hline 5 & Selar, Selaroides sp & 0,03157 & 0,12469 & 0,15626 & 0,79798 \\
\hline 6 & Peperek, Leiognathus spp & 0,04882 & 0,18757 & 0,23639 & 0,79348 \\
\hline 7 & Talang-Talang, Scomberoides sp & 0,10934 & 0,17651 & 0,28585 & 0,61748 \\
\hline 8 & Kuwe, Caranx sp & 0,03480 & 0,53291 & 0,56771 & 0,93870 \\
\hline 9 & Gole-Gole, Alectis sp & 0,15707 & 0,19474 & 0,37670 & 0,51698 \\
\hline 10 & Barakuda, Sphyraena sp & 0,03219 & 0,24957 & 0,28175 & 0,88577 \\
\hline 11 & Layang, Decapterus sp & 0,07644 & 0,03531 & 0,11175 & 0,31600 \\
\hline 12 & Tenggiri, Acanthocybium sp & 0,08100 & 0,20929 & 0,29029 & 0,72096 \\
\hline 13 & Kakap, Lutjanus sp & 0,04990 & 0,27425 & 0,32415 & 0,84607 \\
\hline 14 & Kerong-Kerong, Therapon spp & 0,22585 & 0,15324 & 0,37909 & 0,40423 \\
\hline 15 & Layur, Trihiurusavala sp & 0,01729 & 0,35833 & 0,37562 & 0,95397 \\
\hline 16 & Tuna, Thunnus sp & 0,20084 & 0,10957 & 0,31041 & 0,35298 \\
\hline 17 & Cakalang, Katsuwonus sp & 0,06936 & 0,17842 & 0,24778 & 0,72009 \\
\hline 18 & Kerapu, Epinephelus spp & 0,05786 & 0,27801 & 0,33586 & 0,82774 \\
\hline 19 & Manyung, Arius spp & 0,03090 & 0,22124 & 0,25214 & 0,87746 \\
\hline 20 & Cumi-Cumi, Lolligo spp & 0,01513 & 0,25326 & 0,26839 & 0,94362 \\
\hline \multicolumn{2}{|c|}{ Jumlah } & 1,30933 & 4,23136 & 5,56556 & 15,1463 \\
\hline \multicolumn{2}{|c|}{ Rata-Rata } & 0,06547 & 0,21156 & 0,27828 & 0,75731 \\
\hline
\end{tabular}




\section{c. Laju Mortalitas Total}

Pendugaan mortalitas total (Z) ikan berdasarkan data panjang dengan metode lenght catchcurve (Sparre dan Venema, 1999).Untuk lebih jelas hasil analisis mortalitas todal jenis ikan yang berada di sekitar kawasan TWP Pulau Pieh dapat dilihat pada Tabel 1.

Berdasarkan hasil penelitian didapatkan mortalitas total tertinggi adalah pada ikan kuwe dengan nilai 0,56771 dan mortalitas total terendah terjadi pada ikan layang dengan nilai 0,1175. Hal ini disebabkan tinggi penangkapan ikan kuwe dan rendahnya penangkapan ikan layang di sekitaran TWP Pulau Pieh.

Menurut (Kartini et al., 2017), bahwa mortalitas total ikan disuatu perairan mempengaruhi stok ikan, dimana terjadinya tekanan penangkapan terhadap spesies ikan dapat menurunkan keragaan reproduksi yang diawali dengan penurunan ukuran pertama kali ikan matang gonad. Pada ikan betina, kondisi ini akan menurunkan fekunditas sehingga dapat mengurangi keberhasilan rekrutmen ikandi alam (Ernawati dan Kamal, 2017). Oleh karena itu, kegiatan eksploitasi yang dilakukan terhadap sumber daya ikan seharusnya memperhatikan tata cara penangkapan yang ramah lingkungan, seperti tidak menggunakan bahan peledak dan racun ikan, menggunakan mata jaring dengan ukuran tertentu (Adam, 2012).

\section{d. Laju Eksploitasi}

Hasil analisis data panjang total ikan sampel dan dengan menggunakan rumusrumus laju mortalitas, didapatkan laju mortalitas alami (M), laju mortalitas penangkapan $(\mathrm{F})$, laju mortalitas total $(\mathrm{Z})$ dan laju eksploitasi seperti yang disajikan pada Tabel 1.

Dari Tabel1. terlihat bahwa jenis ikan yang laju eksploitasi yang tertinggi terdapat pada ikan kembung yaitu 0,97421, sedangkan laju eksploitasi terendah terdapat pada ikan layang yaitu 0,31600. Dapat dilihat juga eksploitasi tinggi yang sudah melebihi tingkat eksploitasi maksimum yaitu 0,5 terdapat juga pada ikan - ikan lainnya seperti ikan layur, cumi - cumi, ikan tongkol, ikan kuwe, ikan teri, ikan barakuda, ikan manyung, ikan gole - gole ikan kakap, ikan kerapu, ikan selar, ikan sarden, ikan peperek, ikan tenggiri, ikan cakalang dan ikan talang - talang. Dari ke 17 jenis ikan tersebut sudah termasuk kedalam eksploitasi berlebihan dimana angka laju eksploitasi melebihi 0,5. Ikan yang mempunyai nilai eksploitasi rendah terdapat 3 jenis ikan yakni ikan layang ikan tuna dan ikan kerong - kerong, dimana ikan tersebut belum mencapai tingkat pemanfaatan optimal yakni masih dibawah 0,5 . Untuk lebih jelas tingkat eksploitasi dapat dilihat pada gambar dibawah ini.

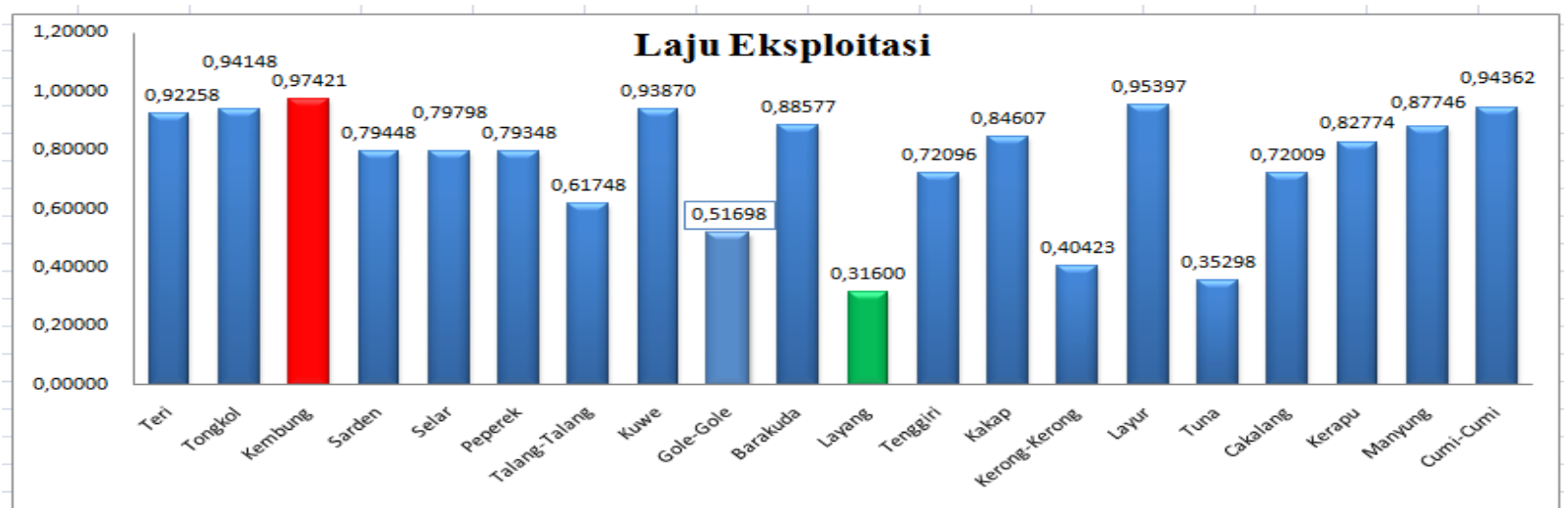

Gambar 1. Laju Eksploitasi per jenis ikan yang tertangkap di TWP Pulau Pieh 
Menurut Brandt (1984); Kristjonnson, (1959) alat tangkap payang merupakan alat tangkap yang bersifat aktif mengejar dan mengurung gerombolan ikan pelagis agar masuk ke dalam jaring payang. Hal ini sesuai dengan pendapat (Brandt, 1984; Kristjonnson, 1959), bahwa payang adalah pukat kantong yang digunakan untuk menangkap gerombolan ikan, kedua sayapnya berguna untuk menakut-nakuti atau mengejutkan serta menggiring ikan untuk masuk ke dalam kantong dan cara operasinya adalah dengan melingkari gerombolan ikan dan kemudian pukat kantong tersebut ditarik kearah kapal. Kondisi sumberdaya ikan di kawasan TWP Pulau Pieh sudah mengalami overfishing disebabkan laju eksploitasi yang tinggi dengan rata- rata laju eksploitasi 0,75731.

Menurut (Sapriyadi dan Zulfikar, 2012), menyatakan bahwa laju eksploitasi ikan yang tinggi dapat mengakibatkan terjadinya overfishing di suatu perairan sedangkan (Sarianto et al., 2017) menyatakan makain banyak ikan yang tertangkap dalam ukuran kecil menandakan perairan tersebut telah terdegradasi. Hal ini sesuai dengan hasil penelitian yang menunjukkan hasil eksploitasi rata - rata ikan yang berada di TWP Pulau Pieh berada dalam kondisi overfishing dengan rata - rata nilai eksploitasinya 0,75731. Menurut (King, 1995), menyatakan bahwa spesies yang dieksploitasi berlebihan akan berdampak pada tereduksinya ikan-ikan dewasa sehingga ikan ikan dewasa tersebut lebih dulu ditangkap oleh aktivitas penangkapan sebelum sempat untuk melakukan pemijahan minimal sekali dalam siklus hidupnya.

Tabel 2. Laju Eksploitasi Menurut Besaran Eksplotasi Jenis Ikan

\begin{tabular}{|c|c|c|}
\hline No & Laju Eksploitasi & Jenis Ikan \\
\hline 1 & $>0,9$ & $\begin{array}{ll}\text { - } & \text { Teri } \\
\text { - } & \text { Tongkol } \\
- & \text { Kembung } \\
\text { - } & \text { Kuwe } \\
\text { - } & \text { Layur } \\
- & \text { Cumi - Cumi }\end{array}$ \\
\hline 2 & $\mathbf{0 , 7 1}-\mathbf{0 , 8 9}$ & $\begin{array}{ll}\text { - } & \text { Sarden } \\
\text { - } & \text { Selar } \\
\text { - } & \text { Peperek } \\
\text { - } & \text { Barakuda } \\
\text { - } & \text { Tenggiri } \\
\text { - } & \text { Kakap } \\
\text { - } & \text { Cakalang } \\
\text { - } & \text { Kerapu } \\
\text { - } & \text { Manyung }\end{array}$ \\
\hline 3 & $\mathbf{0 , 5 1}-\mathbf{0 , 7 0}$ & $\begin{array}{ll}- & \text { Talang - Talang } \\
\text { - } & \text { Gole - Gole }\end{array}$ \\
\hline 4 & $<0,5$ & $\begin{array}{ll}- & \text { Layang } \\
- & \text { Kerong - Kerong } \\
- & \text { Tuna }\end{array}$ \\
\hline
\end{tabular}


Pengelolaan penangkapan ikan yang berlebihan dapat dilakukan dengan pengaturan mata jaring, dan pengaturan ukuran panjang ikan minimum yang boleh diambil. Langkah-langkah pengelolaan tersebut dapat dituangkan di dalam kesepakatan desa,seperti yang sudah dilakukan pada jenis-jenis ikan kerapu (Yuliana et al., 2016) kesepakatan desa tersebut mengatur secara adat dan diawasi oleh masyarakat sendiri tentang alat tangkap yang boleh digunakan, panjang minimum ikan yang boleh ditangkap, termasuk pelarangan penangkapan ikan ketika musim memijah. Yuliana et al., (2016) mengungkapkan bahwasanya laju eksploitasi (E) ikan yang masih dibawah pemanfaatan optimum $(0,5)$ kegiatan pemanfaatan masih dapat ditingkatkan sampai mencapai batas optimum dengan cara meningkatkan upaya penangkapan. Adapun ikan yang masih dapat ditingkatkan hasil tangkapannya adalah ikan layang, tuna dan kerong - kerong yang tingkat laju eksploitasinya sangat rendah yakni dibawah pemanfaatan optimum $(0,5)$, dan ada 16 jenis ikan yang telah melebihi batas optimun pemanfaatan, hal ini dapat memacu berkurangnya stok ikan di sekitar TWP Pulau Pieh.

\section{KESIMPULAN DAN SARAN}

\section{Kesimpulan}

1. Dari hasil analisis perhitungan eksploitasi ini menunjukan bahwa :

- Tingkat eksploitasi ikan di TWP Pulau Pieh dengan rata - rata nilai eksploitasi 0,75731, laju eksploitasi tertinggi terdapat pada jenis ikan Teri, Tongkol Kembung, Sarden, Selar, Peperek, Talang - Talang, Kuwe, Barakuda, Tenggiri, Kakap, Layur, Cakalang, Kerapu, Gole Gole, Manyung dan Cumi - Cumi dengan besaran eksploitasi $>0,5$.
- Laju Eksploitasi Terendah terdapat pada jenis ikan Layang, Tuna dan Kerong kerong yang masih dibawah angka ketetapan $<0,5$, sehingga masih dapat dimanfaatkan secara optimal.

2. Kondisi sumberdaya ikan di TWP Pulau Pieh :

- Sumberdaya Ikan di TWP Pulau Pieh sudah mengalami overfishing atau kelebihan tangkap karenakan tingginya laju eksploitasi penangkapan.

- Alat tangkap yang digunakan memiliki tingkat selektifitas yang rendah dimana seluruh ukuran ikan ditangkap sehingga mengurangi kesempatan untuk ikan berkembang tentunya dapat mengakibatkan kelebihan tangkap (overfishing).

\section{Saran}

Berdasarkan hasil penelitian di sekitar kawasan Taman Wisata Perairan (TWP) Pulau Pieh telah mengalami overfishing karena laju eksploitasi yang tinggi. Oleh karena itu perlu dilakukan penelitian lebih lanjut tentang pendugaan stok ikan di sekitar kawasan TWP Pulau Pieh untuk mendapatkan gambaran optimalisasi pengoperasian alat tangkap

\section{DAFTAR PUSTAKA}

Adam, L. (2012). Sustainable Fisheries Development Policy (Case Study: Wakatobi District, Southeast Sulawesi Province And Morotai Island District, North Maluku Province. Jurnal Perikanan Dan Kelautan, 2(2).

Aziz, K. A. (1989). Dinamika populasi ikan. Bahan Pengajaran Departemen Pendidikan Dan Kebudayaan Direktorat Jenderal Pendidikan 
Tinggi Pusat Antara Universitas Ilmu Hayat. IPB. Bogor. 89hlm.

Beverton, R. J., \& Holt, S. J. (2012). On the dynamics of exploited fish populations (Vol. 11). Springer Science \& Business Media.

Charles, A. T. (2001). Fishery conflicts and the co-management approach. In Sustainable Fisheries Systems. London: Blackwell Science.

Effendie, M. I. (1997). Metode Biologi Perikanan, Bagian Perikanan, Bagian I. Yayasan Dwi Sri Institut Pertanian Bogor. Bogor.

Ernawati, Y., \& Kamal, M. M. (2017). Pengaruh laju eksploitasi terhadap keragaan reproduktif ikan tembang (Sardinella gibbosa) di perairan pesisir Jawa Barat. Jurnal Biologi Indonesia, 6(3).

Kartini, N., Mennofatria, B., \& Affandi, R. (2017). Pola rekrutmen, mortalitas, dan laju eksploitasi ikan lemuru (Amblygaster sirm, Walbaum 1792) di perairan selat sunda. Biospecies, 10(1).

King, M. (1995). Fisheries biology: Assessment and Management. Ed Fishing New Books, Osney Mead. Oxford Ox.KKP-RI. 2014. Keputusan Menteri Kelautan dan Perikanan Republik Indonesia Nomor 38/KEPMEN-KP/2014 tentang Rencana Pengelolaan dan Zonasi Taman Wisata Perairan Pulau Pieh dan Laut Sekitarnya di Provinsi Sumatera Barat Tahun 2014 - 2034. Kementerian Kelautan dan Perikanan Republik Indonesia.

Kristjonnson, H. E. D. (1959). Modern fishing gear of the world (1).

Pauly, D. (1984). Fish population dynamics in tropical waters: A manual for use with programmable calculators (Vol. 8). WorldFish.
Sangaji, J., Kusumastanto, T., \& Simanjuntak, S. M. (2014). Analisis depresiasi dan kebijakan pengelolaan sumberdaya ikan layang di wilayah perairan Kota Ambon. Journal of Agriculture, Resource and Environmental Economics, 1(1).

Sapriyadi, T. E., \& Zulfikar, A. (2012). Kajian Mortalitas Dan Laju Eksploitasi Ikan Ekor Kuning (Caesio Cuning) Dari Laut Natuna Yang Di Daratkan Pada Tempat Pendaratan Ikan Barek Motor Kelurahan Kijang Kota. University Maritime Raja Ali Haji.

Sarianto, D., Simbolon, D., \& Wiryawan, B. (2017). Dampak Pertambangan Nikel Terhadap Daerah Penangkapan Ikan di Perairan Kabupaten Halmahera Timur. Jurnal Ilmu Pertanian Indonesia, 21(2), 104-113.

Sparre, P., \& Venema, S. C. (1999). Introduksi pengkajian stok ikan tropis. Buku I. Manual. Pusat Penelitian Dan Pengembangan Perikanan. Jakarta. 438p.

Tangke, U. (2010). Analisis potensi dan tingkat pemanfaatan sumberdaya ikan kuwe (Carangidae sp) di perairan Laut Flores Propinsi Sulawesi Selatan. Agrikan: Jurnal Agribisnis Perikanan, 3(2), 31-38.

Yuliana, E., Boer, M., Fahrudin, A., Kamal, M. M., \& Muttaqin, E. (2016). Status stok ikan karang target di kawasan konservasi Taman Nasional Karimunjawa. Jurnal Penelitian Perikanan Indonesia, 22(1), 9-16. 